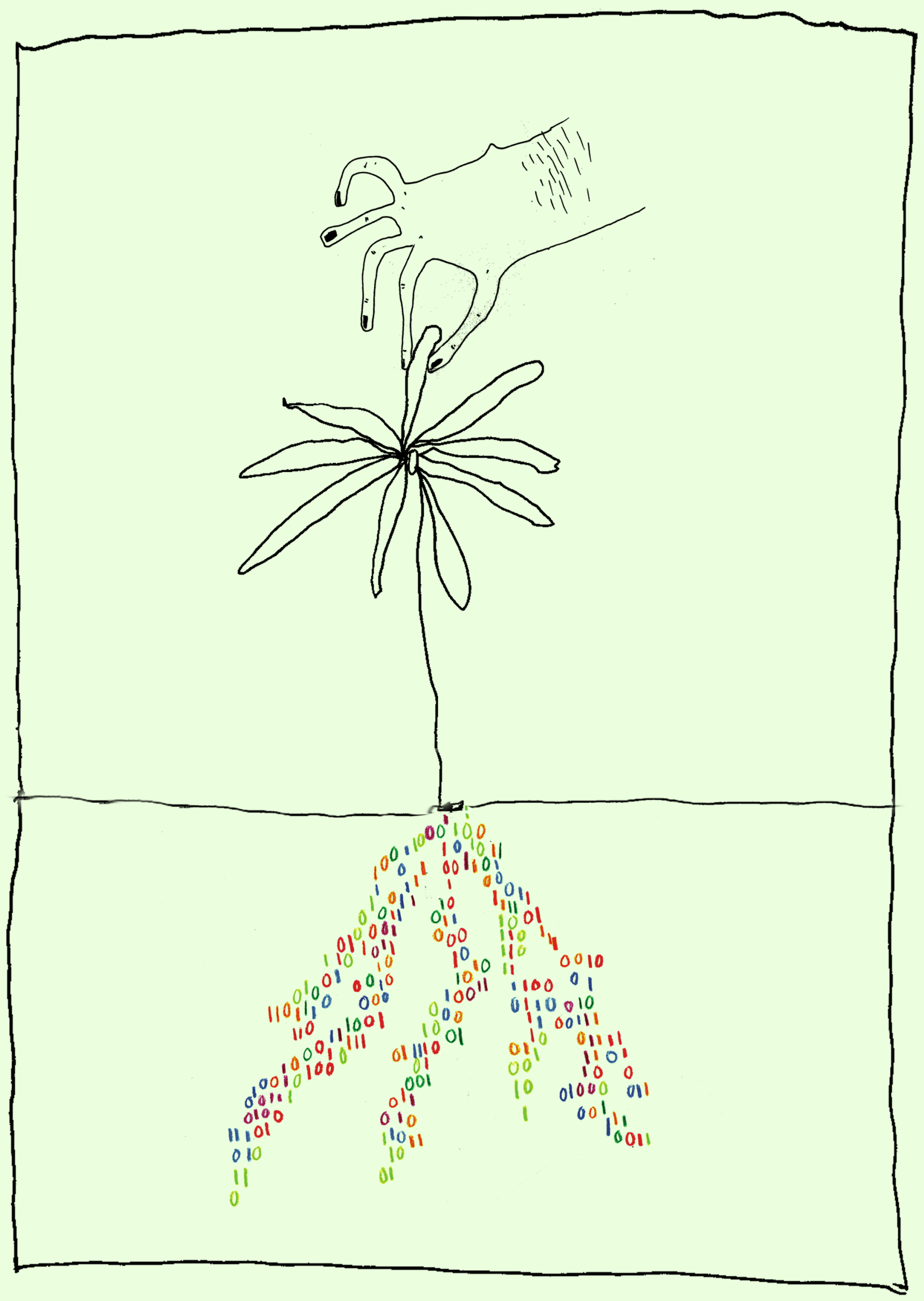


Automata

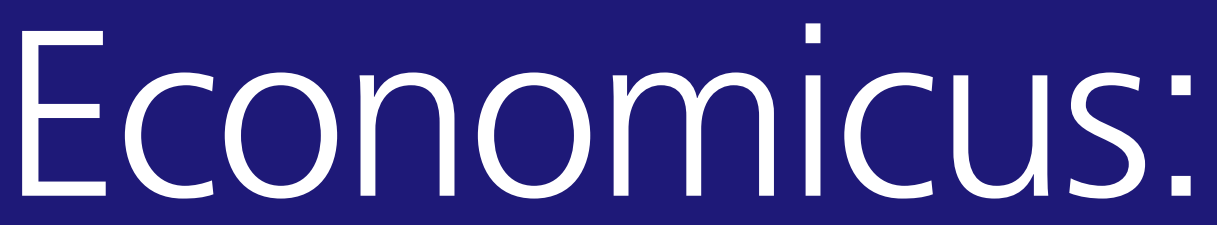

Machines that

Create Value

and the Artificial

Creative Economy

Guilherme Fráguas Nobre 


\section{Automata Economicus: Machines that Create Value and the Artificial Creative Economy}

\section{Guilherme Fráguas Nobre}

fraguasnobre@gmail.com | Profesor de la Universidad Federal del ABC, Brasil. Investigador Asociado, Instituto de Tecnología de Comunicación de la Ciencia.

Fecha de recepción: 28 de agosto de 2017 | Fecha de aceptación: 04 de abril de 2018

\section{Resumen}

El artículo presenta el automata economicus para contrastar con el concepto de machina economicus: este último tiene como objetivo construir modelos basados en software que imiten agentes, entornos, sistemas y herramientas humanos (es decir, un homo economicus artificial); mientras que el primero apunta a máquinas autónomas capaces de una nueva creación / conversión de valor económico. El artículo afirma que una economía poblada con varios automata economicus puede dar origen a una economía creativa artificialmente inteligente (ECAI). Finalmente, el artículo sostiene que tales automata economicus pueden eventualmente difuminar la distinción tradicional de la economía entre capital, tierra y trabajo.

Palabras clave | automata economicus, machina economicus, homo economicus, economía creativa, clase creativa. 
AUTOMATA ECONOMICUS: MACHINES THAT CREATE

VALUE AND THE ARTIFICIAL CREATIVE ECONOMY

\begin{abstract}
The paper introduces the automata economicus to contrast with the concept of machina economicus: the latter aims to build software-based models that mimic human agents, environments, systems, and tools (i.e., an artificial homo economicus); whereas the former aims autonomous and creative machines capable of new economic value creation/conversion. The paper states that an economy populated with several automata economicus may give birth to an artificially intelligent creative economy (AICE). Finally, the paper sustains that such automata economicus may eventually make fuzzy the economics' traditional distinction between capital, land, and labor.
\end{abstract}

Keywords | automata economicus, machina economicus, homo economicus, creative economy, creative class. 


\section{Introducción}

Economics usually separates the inputs between capital, labor, and land - for they have been a fair proxy to what, by whom, and where it takes to produce marketable value. Usually, the resources are brought to a facility filled with machines (capital), facility and resources that have been spatially located and under someone's property rights (land), and which are expected to be worked by human employees along the systems and processes (labor).

But what happens if artificially intelligent (Al) machines replace the human labor, doing so partially in virtual environments such as the internet? For example a machine in the form of an algorithm performing, at the 'clouds,' tasks that were supposed to be carried out by human employees. In this scenario, such machine would represent a dematerialized 'capital' functioning into the cyberspace (a virtual 'land'), and eventually also replacing the traditional 'labor.'

The point is quite simple: such machine would embody mixed traits of capital, labor, and land at the same time. More than that, artificially intelligent machines have been programmed to become creative: once capable of generating innovation and discovery by themselves, Al machines can be seen as assets that create new marketable value in a very autonomous way. Some authors have registered Al-powered innovation and invention in arts, production, news, and science (see Section 4).

Although the sectors that traditionally come together as to define the creative economy do include the technology-intensive ones (e.g., games, software, robotics, etc.), here the Al assets are taken as the very forefront of the creative economy. Moreover, even as an 'independent' creative economy itself - given both the agents and the creativity are not human. Thereupon, such artificial productive vanguard represents an original way to think and study the new Al creative economy. 


\section{Computational Economics ${ }^{1}$}

Econometrics can be defined as the use of mathematical, statistical, and computational reasoning and tools over data that may have economic relevance. From this point of view, the conjunction between economics and the computer sciences is merely instrumental, with no necessary interdisciplinary amalgamation. For instance: a casual software adoption to deal with a database does not mean that the economist is also a computer scientist; nor that the computer scientist who participated in this software programming should ever be confused with an economist.

There is a distinction to be made in the use of simulation models by computer scientists, who, in writing code, are acting as engineers do when they design new structures or processes, and the use of computer simulations by social scientists in general, and economists in particular, who, at least to begin with, are interested not in changing the world through their designs but in understanding the world. (Marks and Vriend, 2012, p. 116)

However, the concomitant interplay between economics and computer science has given rise to a new field of research - the computational economics. According to the Society for Computational Economics:

Computational economics explores the intersection of economics and computation. These areas include agent-based computational modeling, computational econometrics and statistics, computational finance, computational modeling of dynamic macroeconomic systems, computational tools for the design of automated Internet markets, programming tools specifically designed for computational economics, and pedagogical tools for the teaching of computational economics. (comp-econ.org)

1 The Artificial Economics belongs to the field of Computational Economics (Izquierdo et. al., 2016, p. 40). 
It is worth to note the tendency to model 'agents,' 'environments,' 'systems,' and 'tools,' meaning: agents such as consumers, environments such as markets, economic systems such as institutional arrangements, and economic tools as the ones used by policy-makers. In the first case, the computational modeling of the economic agents resulted in an individual branch of research named 'agent-based computational economics' (ACE). In Richiardi's words:

In a nutshell, agent-based models (ABMs) are models, that is, abstract representations of the reality, in which (i) a multitude of objects interact with each other and with the environment, (ii) the objects are autonomous, that is, there is no central, or 'top-down' control over their behavior, and (iii) the outcome of their interaction is numerically computed. Since the objects are autonomous, they are called 'agents.' The application of agent-based modeling to economics has been labeled agent-based computational economics (ACE). (Richiardi, 2012, p. 137)

These agent models recall one of the touchstones of economics, the homo economicus, implied in 1848 by John Stuart Mill: "Homo economicus or economic man is an individual that acts to maximize his well-being given the constraints he faces. (He is) a particular abstraction in relation to human nature (and) embodies: 1) instrumental rationality; and 2) material self-interest". (Rodriguez-Sickert, 2009, p. 1-2) In fact, part of the ACE effort concentrates in modeling and programming the homo economicus or its variants - computationally crafted less-rational and less-selfish agents; and how such agents interact with each other given their artificial environments, systems, and tools. 


\section{Automata Economicus ${ }^{2}$}

Some authors have been proposing the "machina economicus" as: "a synthetic homo economicus (also) described as the perfectly rational machines" (Prause, 2017); "intelligent agents that can learn and reason effectively in economic contexts, including reasoning about other agents" (Lin, 2016); "a synthetic homo economicus, the mythical perfectly rational agent of neoclassical economics" (Parkes, Wellman, 2017, p. 267); and "Artificially Intelligent DAOs (Machina Economicus) will prevail on blockchains that will make rational decisions on behalf of humans" (Bashir, 2017, p. 484).

However, few authors do prefer seeing such a concept as the "interacting populations of algorithms" (Balduzzi, 2016, p. 4); "Als of greater-than-human intelligence (that cooperate as a community)" and probably will replace humans as labor (Hall, 2008, p. 461,464); or even as:

A computer that would achieve (a) New Creative Economic Model

that describes the real distribution based environmental conscious economic market system, new structural laws of demand and supply, and the public monetary system immediately, hence building a much better world sustainable economic system. (Luyima, 2016).

These approaches are attuned with the researches done in the field of computational economics, since they aim the economic agents modeling and programming in themselves or their interaction with each other; and refer to their potential vicarious role as to replace humans or human characteristics/behaviors. For example, artificial agents that reason, make decisions, and eventually 'steal' jobs (Jones, 2016). However, the concept of 'machina economicus' seems to miss a fundamental point: the capacity to generate/actualize economic value. In order to propose something different, the artificial agent that is able to generate/actualize economic value in a very autonomous, creative, and sustainable way is here named "automata economicus".

2 The term 'automata' is based on Moulin (1992). Despite that may be an error of concordance, since in Latin 'automata' is feminine and 'economicus' is masculine - the expression is retained so to recall the homo economicus. 
AUTOMATA ECONOMICUS: MACHINES THAT CREATE

VALUE AND THE ARTIFICIAL CREATIVE ECONOMY

'Communications' have been modeled and programmed into machines, that evolved to become artificial social/economic agents. (...) Such expressive machines are of interest because they have been programmed to be both creative and autonomous, but mostly because they function as assets that generate other assets. That means the following: machines that communicate and produce economic tradeable goods/services do enact as an independent creative sector - so to say. Machines that design copyrightable/patentable material are in the forefront of the creative economy, and bring at least few questions about their role to foster dematerialization and immaterialization, economic growth and human development, rebound or sustainability for instance. (Nobre, 2018, p. 12)

Such machines, sometimes in the form of algorithms, do create new economic tradeable value autonomously (with none human intervention) - eventually also acting to trade such a good or service directly. Therefore, the focus relies instead on the machines' value creation and value realization (automata economicus), instead of over software/hardware that try to reproduce or mimic the human economic agents, environments, systems, or tools (machina economicus). Such automata economicus are "artificially intelligent assets that create other assets. (An) artificial 'creative capital' or 'creative class' designed to generate value and engender economic wealth virtually by their own - subverting the notions of capital and labor as separate issues." (Nobre, 2018)

Matuck and Nobre (2016) have presented examples of machines capable of communication, creativity, art production (such as painting, music, sculpture, writing), and technical writing (such as journalist texts). Moreover, Matuck and Nobre have also introduced cases of machines performing persuasion (in political and selling contexts), scientific discovery, and generating patentable/copyrightable content as well (2016). 


\section{Assets creating value}

In order to propose the expression automata economicus as a new meaningful category, it is necessary to introduce some examples of such 'assets that create value'. Moreover, examples of machines able to generate/actualize economic value in a very autonomous, creative, and sustainable ${ }^{3}$ way. First, it is worth to note: (1) machines may generate or create economic value without participating in how it would be made effective and available to humans; (2) machines may be involved in how the value is actualized (i.e. marketed) and made available to humans without participating in how it was originated; or (3) machines may be related to both activities and processes.

Some authors have been presenting machines capable of value-generation through creative art production, technical writing, scientific discovery, and patents/copyrights. For instance, machines that paint (Sundararajan, 2014; Moroni, Zuben, Manzolli, 2002), write novels and poems (Dupej, 2012; Voisen, 2010; Bringsjord, Ferrucci, 2000), compose music (Strycker, 2012; Colton, Wiggins, 2012), enact as architects (Boden, 2000, p. 74), that write down journalistic news (Carlson, 2015; Aires, 2016; Weeks, 2014), scientific papers/abstracts (Conner-Simons, 2015; Jordan, Rose, 2010), fill patent application forms (Breitinger, Elmaghraby, Gipp, Hamborg, 2017), that promote scientific discovery (Dzeroski, Langley, Todorovski, 2007; Bridewell, Langley, 2010; Langley, 2013) and develop patentable/ copyrightable material (Davies, 2011; Buning, 2015; Hattenbach, Glucoft, 2015). In each of these activities, such machines are creating new economic value, mostly in an autonomous and creative manner.

Otherwise, there have been authors citing machines that work as marketers - i.e. whose business is to trade already existing value. Such services-providers also generate economic value, since they eventually do it faster, cheaper, and sometimes in a more effective way than their human counterparts - therefore 'fabricating' enhanced-productivity through artificial

3 The potential sustainability of such automata economicus is related to the phenomenon of Singularity (Nobre, Clemente and Souza, forthcoming), which is not the object of this work. 
intelligence and genetic algorithms. For instance, machines apt of value-conversion as financial analysts, risk managers, (Alam, Kendall, 2017; Das, 2017), traders (Maney, 2016; Marwala, 2015), investment advisors (Silva, 2017), legal assistants (Middlemass, 2017; Duzer, 2017), insurance brokers (Bharal, Shapiro, 2016), healthcare 'strategists' (Schatsky, Petrov, Ronanki, 2017; PCW, 2017; Hamid, 2016), and so on.

A good image is one machine painting a canvas that a person may want to buy (value creation), and other machine working as a broker so to sell such canvas online (value conversion) - at e-Bay for instance. Or, one machine writing a novel that a person may want to read (value creation), and other machine creating an e-book and uploading it to the Kindle Store (value conversion) - see (Andersen, Pold, 2014). Even more, one machine composing music and producing records (value creation), and other machine making them available to sell at iTunes (value conversion). Plus, machines or bots using consumers' internet footprints to marketing their silicon peers' canvas, e-books, and records. Finally, one machine is developing a potentially marketable technical solution (value creation), and another machine is filling a patent form that may be granted (value conversion). That could be the case for the design and architectural solutions, for example.

\section{The new creative economy}

There is no single definition of 'creative economy', nor a simple way to select the sectors that come together so to compose it. For example, Unesco $(2013$, p. 22) presents a table with six different models on how to group such sectors. Nonetheless, all the models bear a common trait: they assume the human creativity as their cornerstone. In this perspective, the creative persons are the real value-creators, value-dealers, and value-usufructuaries. In short, the 'creative economy' has been treated as a conjunction of 'human creativity' with 'economic value from, by, and to humans'. It is not too much to stress: something exclusively human-centered. According to Nobre (2018): 
AUTOMATA ECONOMICUS: MACHINES THAT CREATE

VALUE AND THE ARTIFICIAL CREATIVE ECONOMY

The 'creative economy' has been taken mostly as a rearrangement of traditional sectors into a new label and has generally been quantified through the dollar-unit. Whatever escapes from the market, prices, monetization, and commercialization, also evades from its domain. The 'creativity' itself has been treated as a black box, a factor that one can attract and maintain (via the creative class, Richard Florida's biome) under special circumstances of habitat (with talent, tolerance, and technology providing a propitious environment). (p. 153)

However, given that 'creativity' may be programmed in and developed by machines (Boden, 2009), and as soon as such machines become apt to generate and trade 'economic value' by their own, then the meaning of 'creative economy' shall change. In other words: whenever artificially intelligent machines (embedded with Genetic Algorithms so to evolve) do create and actualize novel economic value in a very autonomous and creative way, then it is necessary to re-think the 'creative economy'. First, creativity is no longer an exclusive domain of humans. Second, despite only humans remain as its usufructuaries, now novel economic value is found flowing 'from and by machines' as well. Therefore, such artificially intelligent creative economy (AICE) is partly an unprecedented phenomenon - which is an economy populated with automata economicus able to engender-actualized value.

\section{AICE's economic impact}

The conjugation of artificial intelligence, machine learning, and genetic algorithms are changing the 'rules of the game' we are used to. Machines able to learn and to rewrite their own code to evolve; capable to interact, communicate, express themselves creatively, and of introducing new products, services, and processes; such machines are the 'silicon side' of the new economy.

An economy filled with these machines is expected to present increasing economic growth rates. Actually, increasing and accelerating rates - tracing an asymptotic upward line. Some authors name such phenomenon as 'economic singularity': "The (rapid) growth in computation and artificial intelligence will cross some boundary or Singularity after which 
economic growth will accelerate sharply as an ever-accelerating pace of improvements cascade through the economy." (Nordhaus, 2015)

The economic impact of automation has been a major issue to policy-makers. That means the economic impact of the silicon side (machines) over humans' lives - here called the 'carbon side'. For example, some authors have been calling attention to key points such as unemployment and the historical tendency of fall on the wages' share at GDP: About 'two thirds of all jobs' developing countries might lose to automation" (Corpuz; Caughill, 2016);

"we examine how susceptible jobs are to computerization. According to our estimates, about 47 percent of total us employment is at risk" (Frey; Osborne, 2013); and "(that) is the very essence of the Second Machine Age hypothesis. It would manifest itself in weaker than expected wage growth and a secular fall in the labor share of income. (Haldane, 2015)

Although the optimists believe in new jobs creation and old-skills rechanneling, partly recalling what happened in the previous industrial revolutions, some argue that this time is qualitatively different. The current Revolution 4.0, they say, is fast and deep enough to avoid any 'catching up'. Such disruptive reality may increasingly displace human labor (including high skilled areas as medicine, financial system, and legal affairs) and also intensify the income concentration in society (towards the machines proprietors' hands). 


\section{Conclusion}

This paper has introduced at least two original features: the automata economicus and the artificially intelligent creative economy (AICE). The latter is populated with various automata economicus, that work to engender and actualize new economic value - doing so in a very autonomous and creative manner.

Machines able to act as independent economic agents (not only as social agents), embedded with genetic algorithms (Gl) and artificial intelligence (Al), capable of innovation without human intervention, whose discoveries may be conducive to copyrights and patents. In short, machines that create and trade marketable value by their own. Machines that invent fresh wealth, in addition to the GDP accountable to humans and their tools (including devices and dumb-machines). Machines that replace arms and bodies do exist for decades (e.g. 'memory' registers and calculation skills), but not machines that can perform intelligence and creativity. Coexisting with the homus economicus, such automata economicus are the very embodiment of the creative economy: an object that has demanded a huge investment in P\&D to arise, until reaching a point from where it can go ahead alone - to produce novel art, unforeseen knowledge, goods, and services. (Nobre, 2018, p. 155)

The paper has chosen to focus on such machines' capacity to generate/convert new economic value, instead of on the possibility of programming machines to mimic human agents, environments, systems, and tools. Also, it highlighted the potential to such automata economicus to constitute a new creative economy and creative class - artificial in both cases. That is a remarkable shift when one recalls that the creative economy was always thought as necessarily human. Finally, artificially intelligent assets that invent and construct other (dumb-or-not) assets, breeding novel value, make fuzzy the economics' traditional distinction between capital, land, and labor.

Last but not least, since automation may bring advantages and disadvantages, it is necessary to think on how to balance automation and social issues; the new silicon-carbon interfaces. 
An economy full of machines that interact and respect their human counterparts, and that eventually work together or at least not against each other. Also, an economy with machines that contribute to "relax, retrain, and redistribute" (Haldane, 2015, p. 15), that help delivering social benefits (e.g. as personal caregivers, elderly companions, automated nurses and doctors etc.), creating income, and alleviating the "ill effects of inequality" (West, 2015, p. 12). The incoming future demands to consider machines as part of the solution for the problems they will largely engender. 


\section{References}

Aires, J. P. B. (2016) Automatic Generation of Sports News. Dissertation, University of Porto, Porto, Portugal.

Alam, N. \& Kendall, G. (2017) Here's why robots could be the future of finance. World Economic Forum, $06 \mathrm{Jul}$.

Andersen, C. U. \& Pold, S. B. (2014) Post-digital books and disruptive literary machines. In: Formules 18, pp. 164-183.

Balduzzi, D. (2016) Grammars for Games: A GradientBased, Game-Theoretic Framework for Optimization in Deep Learning. Frontiers in Robotics and Al, Vol. 2, Article 39, Jan. 2016.

Bashir, I. (2017) Mastering Blockchain. Packt Publishing Ltd., Birminham, UK.

Bharal, P. \& Shapiro, L. (2016) Al - the potential for automated advisory in the insurance industry. Acord/Surely. Retrieved from: http://bit.ly/AcordSurely

Boden, M. A. (2000) State of the art: computer models of creativity. The Psychologist, v. 13, e. 2, pp. 72-77.

Boden, M. A. (2009) Computer models of creativity. Al Magazine, V. 30, N. 3, pp. 23-34.

Breitinger, C., Elmaghraby, M., Gipp, B., \& Hamborg, F. (2017). Automated Generation of Timestamped Patent Abstracts at Scale to Outsmart Patent-Trolls. BIRNDL@SIGIR.

Bridewell, W. \& Langley, P. (2010) Two kinds of knowledge in scientific discovery. Topics in Cognitive Science 2, pp. 36-52.

Bringsjord, S. \& Ferrucci, D. A. (2000) Artificial intelligence and literary creativity: inside the mind of Brutus, a storytelling machine. Computational Linguistics, v. 26, n. 4, pp. 642-647.

Buning, M.d.C. (2015) Is the EU exposed on the copyright of robot creations?, Robotics Law Journal, vol. 1, no. 3, pp. 8-9.
Carlson, M. (2015) The robotic reporter - automated journalism and the redefinition of labor, compositional forms, and journalistic authority". Digital Journalism, V. 3, Issue 3, pp. 416-431.

Colton, S. \& Wiggins, G. A. (2012) Computational creativity: the final frontier? European Conference on Artificial Intelligence, Montpellier (France).

Conner-Simons, A. (2015) How three MIT students fooled the world of scientific journals. MIT News, Massachusetts Institute of Technology.

Corpuz, E. \& Caughill, P. (2016) In the developing world, two-thirds of jobs could be lost to robots. World Economic Forum, 14th November. Available at: weforum.org/agenda/2016/11/in-the-developingworld-two-thirds-of-jobs-could-be-lost-to-robots

Das, S. R. (2017) Artificial intelligence and deep learning. Santa Clara University. Retrieved from: http://srdas. github.io/Presentations/Al_DeepLearning_Adobe_ May2017.pdf

Davies, C. R. (2011) An evolutionary step in intellectual property rights - artificial intelligence and intellectual property. Computer Law \& Security Review, vol. 27, pp. 601-619.

Dupej, H. (2012) Next generation literary machines: the "dynamics network aesthetic" of contemporary poetry generators. PhD Thesis, University of Calgary.

Duzer, L. V. (2017) Developments in legal research: from Al to Fastcase 7. Whashington County, Oregon, US. Retrieved from: https://www.co.washington. or.us/LawLibrary/Information/upload/Developments_ handout_bib.pdf

Dzeroski, S.; Langley, P. \& Todorovski, L. (2007) Computational discovery of communicable scientific knowledge. In: S. Dzeroski, L. Todorovski (Eds.), Computational Discovery, LNAI 4660, pp. 1-14.

Florida, R. (2002) The rise of the creative class -why cities without gays and rock bands are losing the economic development race. The Washington Monthly, May, pp. 15-25. 
Frey, C. B. \& Osborne, M. (2013) The future of employment. University of Oxford. Available at: https://www.oxfordmartin.ox.ac.uk/downloads/ academic/future-of-employment.pdf

Grimmelmann, J. (2016) Copyright for literate robots. lowa Law Review, vol. 101, pp. 657-681.

Haldane, A. (2015) Labour's share. Speech. Trades Union Congress, London, 12th November. Available at: https://tinyurl.com/nsqmzoo

Hall, J. S. (2008) Engineering utopia. In: Wang, P.; Goertzel, B. \& Franklin, S. (Edts.) Artificial General Intelligence 2008. Proceedings of the First AGI Conferecen, IOS Press, Amsterdam, Netherlands.

Hamid, S. (2016) The opportunities and risks of artificial intelligence in medicine and healthcare. CuSPE, University of Cambridge.

Hattenbach, B. \& Glucoft, J. (2015) Patents in an era of infinite monkeys and artificial intelligence. Stanford Technology Law Review, vol. 32, pp. 32-51.

Ivanov, S. (2017a) Robonomics - principles, benefits, challenges, solutions. Yearbook of Varna University of Managemente, 10, pp. 283-293.

Ivanov, S. (2017b) The robot as a consumer: a research agenda. Marketing: experiences and perspectives Conference, Varna, Bulgaria.

Izquierdo et al. (2016) Economía artificial: una valoración crítica. Revista de Métodos Cuantitativos para la Economía y la Empresa, 22, pp. 36-54.

Jones, M. (2016) Yes, the robots will steal our jobs. And that's fine. The Washington Post, February $17^{\text {th }}$.

Jordan, D. \& Rose, S. E. (2010) Multimedia abstract generation of intensive care data: the automation of clinical processes through Al methodologies. World J Surg. 34(4), pp. 637-45.

Langley, P. (2013) Computational discovery of scientific models: guiding search with knowledge and data. Inaugural Lecture at the University of Auckland, NZ.
Lin, F. O. (2016) Building Machina Economicus. Conference. Athabasca University, Athabasca, Canada. Retrieved from: https://tinyurl.com/ybkyt5mn

Luyima, S. P. (2016) Building a self-conscious MuRatopian Machina Economicus: beyond artificial intelligence. The Market Mogul. Retrieved from: https://tinyurl.com/ydfs4hao

Maney, K. (2016) How artificial intelligence and robots will radically transform the economy. Newsweek, 30/11/2016.

Marks, R. E. \& Vriend, N. J. (2012) The special issue: agent-based computational economics - overview. The Knowledge Engineering Review, Vol. 27:2, 115-122.

Marwalla, T. (2015) Impact of artificial intelligence on economic theory. University of Johannesburg. Retrieved from: https://tinyurl.com/ydbuju3t

Matuck, A. \& Nobre, G.F. (2016) Communicative and artistic machines: a survey of models and experiments on artificial agents. International Journal of Computer, Electrical, Automation, Control and Information Engineering, vol. 10, n. 10.

Middlemass, J. (2017) Post-Brexit strategies: law firms are adopting Al. The Market Mogul, $7^{\text {th }}$ February. Retrieved from: https://tinyurl.com/y7tlf7cc

Moroni, A.; Zuben, F. V. \& Manzolli, J. (2002) ArTbitration: human-machine interaction in artistic domains. Leonardo, Vol. 35, N. 2, pp. 185-188.

Moulin, J-P. (1992) Modifiable automata, self-modifying automata. Acta Biotheoretica 40, pp. 195-204.

Nobre, G.F. \& Matuck, A. (2016) Communicative and artistic machines: some remarks on authorship, copyright, and liability. International Journal of Humanities and Applied Sciences, Vol. 5, No. 2

Nobre, G.F. (2018) Creative economy and sustainable human development - a theoretical approach for convergences and divergences. Doctoral thesis, Universitat de Girona, Girona, Spain. 
Nordhaus, W. D. (2015) Are we approaching an economic Singularity? Information Technology and the future of economic growth. Yale University. Available at: https://tinyurl.com/y7ue2mqq

Parkes, D. C. \& Wellman, M. P. (2017) Economic reasoning and artificial intelligence. Science, vol. 349, Issue 6245. Retrieved from: https://tinyurl.com/ yax2gwe5

Prause, M. (2016) Leveraging Artificial Intelligence \& CE to create machina economicus. Infosys. Retrieved from: https://tinyurl.com/yarlbalb

PWC. (2017) What doctor? Why Al and robotics will define new health. Retrieved from: https://tinyurl. com/yaf2euyv

Reynolds, C; Cassinelli, A. \& Ishikawa, M. (2008) Economically autonomous robotic entities. International Conference on Robotics and Automation, ICRA'07, Rome, Italy.

Richiardi, M. G. (2012) Agent-based computational economics: a short introduction. The Knowledge Engineering Review, Vol. 27:2, 137-149.

Rodriguez-Sickert, C. (2009) Homo economicus. In: Peil, J.; Staveren, I. V. (Edts.) Handbook of Economics \& Ethics. Edward Elgar Publishing, Cheltenham (UK)/Northhampton (USA).

Schatsky, D; Petrov, P. \& Ronanki, R. (2017) Cognitive technologies for wealth plans - using artificial intelligence to meet new market demands. Delloite University Press.
Silva, J. F. (2017) The economics of artificial intelligence. The Market Mogul, 23th April. Retrieved from: https://tinyurl.com/yahlomsd

Strycker, J. (2012) Artificial intelligence and the arts. Createquity. Available at: http://createquity. com/2012/10/artificial-intelligence-and-the-arts/

Sundararajan, L. (2014) Mind, machine, and creativity: an artist's perspective. Journal of Creative Behavior, Volume 48, Issue 2, pp. 136-151.

UNESCO (2013) Creative economy report - widening local development pathways. Special Edition. Retrieved from: http://tinyurl.com/ljufl28 Access: $12 / 01 / 2017$.

Voisen, S. E. (2010) Computational generation of dream-like narrative: reflections on the uncanny dream machine. Master Thesis, University of California.

Weeks, L. (2014) Media law copyright implications of automated journalism. Journal of Intellectual Property and Entertainment Law, New York University, V. 4, N. 1, pp. 67-94.

West, D. M. (2015) What happens if robots take the jobs? The impact of emerging technologies on employment and public policy. Center for Technology Innovation, The Brookings Institute, Washington, DC, USA. 